\title{
ENTRE A INSERÇÃO E A INCLUSÃO DE MINORIAS NAS ORGANIZAÇÕES: Uma análise crítica sob o olhar de jovens trabalhadores
}

\author{
BETWEEN INSERTION AND INCLUSION OF MINORITIES IN \\ ORGANIZATIONS: A critical analysis on the looking of young workers
}

\author{
David Silva Franco \\ Universidade Federal de Minas Gerais \\ davidf.jf@gmail.com
}

Alex Fernandes Magalhães

Universidade Federal de Minas Gerais alexfernandes03@yahoo.com

Kely Cesar Martins de Paiva Universidade Federal de Minas Gerais kelypaiva@ face.ufmg.br

Luiz Alex Silva Saraiva

Universidade Federal de Minas Gerais saraivalas@gmail.com

Submissão: $17 / 07 / 2017$

Aprovação: 13/11/2017

\section{RESUMO}

O discurso da gestão da diversidade surge nas organizações de trabalho propagando a postura socialmente responsável das empresas que promovem ações de inserção de minorias sociais, apresentadas como possibilidade de superação das desigualdades sociais do capitalismo. Todavia, notamos em diversas empresas não haver nada além do cumprimento de exigências legais, como as que determinam que empresas de médio e grande porte contratem jovens aprendizes. Esses jovens, inseridos em um contexto de vulnerabilidade social, por vezes incorporam a própria ideologia hegemônica que os subjuga enquanto minorias sociais. Partindo de uma perspectiva crítica, o objetivo deste artigo é analisar a percepção de jovens aprendizes quanto à inclusão de minorias sociais nas organizações de trabalho. A partir de entrevistas semiestruturadas e posterior análise de conteúdo, pudemos constatar que ainda há um longo caminho rumo à emancipação política, econômica e social dos sujeitos marginalizados por suas diferenças sociais.

Palavras-chave: Minorias Sociais. Jovens Trabalhadores. Gestão da Diversidade. Ideologia. 


\begin{abstract}
The diversity management discourse comes, in work organizations, spreading the social responsible side of companies that promote actions of social minority insertion, presented as possibility of overcoming social inequalities of capitalism. However, there is nothing more than observe legal demands, as those which determinate that companies of medium and big size hire young workers. These young workers insert in a context of social vulnerability sometimes incorporate the hegemonic ideology that subjugate them while social minority. Starting from a critical perspective, the objective of this article is to analyze the perception of young learners about the inclusion of social minorities in work organizations. From semistructured interviews and subsequent analysis of content, we could see that there is still a long way towards the political, economic and social emancipation of the individuals marginalized by their social differences.
\end{abstract}

Keywords: Social Minority. Young Workers. Management Diversity. Ideology.

\title{
1 INTRODUÇÃO
}

Os discursos organizacionais que pregam ações de diversidade e, assim, marcam práticas de inserção de minorias sociais nas organizações, trazem consigo contradições expressivas. Ao se considerar tais práticas como possibilidade de emancipação dos trabalhadores em relação às limitações dadas pelos preconceitos e exclusões, nos deparamos também com uma gestão da diversidade apregoada a valores, crenças, padrões de conduta e racionalidades que visam à manutenção do status quo de um sistema essencialmente marcado por dominação e relações desiguais. De um lado, são evidentes discursos que valorizam a figura humana e suas potencialidades como principal recurso no âmbito organizacional e, de outro lado, encontram-se latentes as intenções de modelagem e manipulação dos sujeitos pela entrega do poder de produção, sem que saiam dos espaços a eles demarcados. Assim, dificilmente se desenvolve uma real consciência das dificuldades que as minorias sociais enfrentam para que, de fato, deixem de se constituir como sujeitos dotados de diferenças que demarcam as características de subjugados. Em um contexto em que todos devem contribuir produtivamente e todos são consumidores em potencial, a gestão da diversidade não se mostra suficiente para escamotear a falta de representatividade de grupos sociais nas instâncias de poder, sendo muitas vezes uma forma de abafar os conflitos sociais.

No capitalismo, não existe exclusão para aqueles que têm a capacidade de geração de valor (a despeito da exclusão das instâncias sócio-políticas de decisão), sendo assim, as organizações têm buscado diversificar sua força de trabalho para que possam lidar melhor com a dinâmica diversa dos consumidores. Nesse sentido, a aplicação de técnicas e diretrizes voltadas à inserção de minorias nas empresas vem se tornando um novo locus de profissionais diversos - entre psicólogos, pedagogos e administradores -, o que requer reflexões sobre o compromisso ético social nas organizações de trabalho sobre as reais possibilidades de superação das desigualdades sociais. Considerando as adversidades geradas pelos processos de marginalização e alienação, a perspectiva aqui tratada nos orienta para o estabelecimento de uma sociedade verdadeiramente democrática por meio da criação de direitos e deveres comuns, de maneira que superemos a intolerância e formas de exclusão ditadas pelas diferenças humanas, como cor de pele, sexo, deficiências, idade, orientação sexual etc. (BARBOSA, 2007). Isto porque diversas práticas ditas como de inclusão de minorias apenas inserem os sujeitos nas organizações de trabalho (como mulheres, jovens carentes e pessoas 
com deficiência). Todavia, em boa parte dessas práticas empresariais, a real integração ainda está distante de se concretizar, por conta de valorações pejorativas atreladas às diferenças, além da demarcação de um ideal de sujeito organizacional atrelado à heteronormatividade hegemônica - homem, branco, heterossexual, sem deficiências físicas ou mentais.

No cenário brasileiro, a partir da criação da Lei de Aprendizagem $n^{\circ} 10.097 / 2000$, as empresas de médio e grande porte se viram obrigadas a destinar parte do quadro de empregados à contratação de jovens aprendizes e, assim, promover a inserção de um público que normalmente possuiria dificuldades de adentrar no mercado de trabalho formal em grandes empresas - por serem jovens em situação de vulnerabilidade social e fazerem parte de um contexto marcado por estigmas e acessos dificultados. Assim, esses jovens, cuja identidade é geralmente marcada por diversas características de minorias subjugadas - pobres, negros e inexperientes - apesar de potencialmente vivenciarem situações de exclusão, por vezes não notam o sistema de dominação ao qual estão sujeitos, incorporando ideologias hegemônicas de meritocracia, democracia racial e discursos de empresas ditas socialmente responsáveis.

Pela problemática aqui exposta, o objetivo deste artigo é analisar a percepção de jovens aprendizes quanto à inclusão de minorias sociais nas organizações de trabalho, com destaque para pobres, negros, mulheres, homossexuais e eles próprios. Os jovens aprendizes são predominantemente de um contexto de carência de recursos, sendo inseridos no mercado de trabalho por uma associação intermediadora, que faz a ligação entre o jovem e a empresa e também oferece cursos profissionalizantes - ações que não necessariamente lhes garantem a inclusão. De modo complementar, buscamos ainda identificar os principais conflitos e impasses vivenciados por esses jovens no âmbito das organizações, assim como elementos significativos quanto às contribuições do trabalho como agente formador e integrador de minorias nas organizações, motivo que justifica, inclusive, a escolha deste público como sujeito de pesquisa.

A perspectiva de análise que adotamos é crítica, devido ao seu caráter emancipatório e aplicado, tal como nos propõe Paula (2008). Sabemos que a escolha por uma abordagem crítica não é fácil, pois nos leva ao engendramento por áreas menos estáveis e seguras que o funcionalismo nas pesquisas sobre o contexto organizacional. Entretanto, entendemos que a problematização aqui colocada evidencia o seu comprometimento em relação a possibilidades de mudanças quanto às formas de opressão e subordinação de trabalhadores às ideologias empresariais, especialmente no caso de minorias sociais. Por isso, chamamos de crítica esta proposta de análise, assim como seu referencial teórico-metodológico nos parece pertinente. Nosso referencial de análise é predominantemente interpretativista, contudo, não desconsideramos as relevantes contribuições do materialismo histórico e dialético de Karl Marx, que procura compreender as contradições elementares na formação e na mudança social dos sujeitos sociais em meio ao modo como produzem concreta e materialmente a vida ao longo da história e nos diferentes contextos.

A interdisciplinaridade é marca presente deste nosso recorte, que recorre a autores das Ciências Humanas e Sociais Aplicadas, como Psicologia, Sociologia e Administração, além de relevantes apontamentos da Filosofia. Esperamos poder abarcar a complexidade dos temas e conceitos aqui propostos, evitando os reducionismos e contribuindo para que os resultados desta pesquisa possam gerar frutos no que se refere à emancipação social dos trabalhadores quanto às amarras e às limitações da consciência nas práticas organizacionais. Ressaltamos que não se pode mais acatar com simplicidade ou ingenuidade o discurso de inclusão e desenvolvimento de pessoas propagado no cenário empresarial como algo que proporciona o bem geral da humanidade, já que as circunstâncias em que são aplicadas as técnicas e os instrumentos do processo de gestão de pessoas são associadas a jogos e disputas por poder, a 
mecanismos de alienação e manipulação psicológica. Assim, esperamos contribuir para a compreensão da complexidade do universo organizacional enquanto ambiente político, tema que já vem sendo ponto constante de estudos e discussões que tratam as organizações de trabalho em seus aspectos processual, fluido e interacionista.

\section{ENTRE A INCLUSÃO E A INSERÇÃO DE MINORIAS NAS ORGANIZAÇÕES}

Destacamos, primeiramente, que o conceito de minoria social não envolve necessariamente o quantitativo percentual dos sujeitos que apresentam em comum determinada característica fenotípica ou comportamental. Neste sentido, ainda que as mulheres ou as pessoas que se denominam como não-brancas (pretas, pardas, indígenas) possam representar, separadamente, grupos demográficos que compõem mais do que $50 \%$ da população brasileira, estes públicos são considerados como minorias sociais pela ausência de representatividade nos âmbitos social, político e econômico, já que não têm participação incisiva junto às esferas de poder e, muitas vezes, carecem de legitimação social quanto às suas capacidades e potenciais. Assim, seriam maiorias populacionais que se comportam como minorias sociais, na dinâmica social.

A questão da inclusão e do desenvolvimento de minorias sociais perpassa por todo espaço de socialização e trocas entre o sujeito e o contexto que o cerca. A família, a comunidade, a escola e a organização de trabalho são aparelhos fundamentais para a promoção da inclusão, já que são essas instituições que dispõem dos recursos simbólicos essenciais para a constituição subjetiva em meio às interações que o sujeito estabelece com os outros à sua volta. Essas instâncias, frequentemente e muitas vezes inconscientemente, reforçam ideologias que asseguram a perpetuidade das relações de poder desiguais na sociedade. Assim, seguindo o referencial de Marx e Engels (2007), consideramos ideologia como um sistema de pensamento que apresenta os interesses de classes específicas como se fossem interesses de toda a sociedade, o que assegura o controle socioeconômico de determinados grupos em detrimento de outros, e age materialmente para conformar os subjugados. Mas, como são dadas as possibilidades de inclusão nas organizações de trabalho no processo de socialização dos sujeitos?

A família, enquanto elemento de socialização primária, oferece um arcabouço cultural que tenderá a delimitar os espaços que os sujeitos serão considerados aptos a ocupar no futuro. Isto porque, a partir da socialização familiar, diversos aspectos da linguagem, traços que denunciam a origem social, as possibilidades de formação de networking, dentre outros, tendem a oferecer ao sujeito aqueles mesmos espaços e trabalhos já vivenciados no histórico familiar. Esta tendência não é determinística, há outras instituições que influem na ascensão social, no entanto, ela exerce influente força na formação do capital simbólico do sujeito, tal como detalhadamente analisado por Bourdieu (2007). Assim, o processo de estigmatização, como propõe Goffman (1988), inicia-se ao se relacionarem a identidade social virtual, isto é, as expectativas que são esperadas pelos sujeitos num dado contexto com base nas legitimações sociais, e a identidade social real - atrelada aos atributos reais que o sujeito porta ou dispõe. Temos então uma contradição já no processo de socialização primária do sujeito que, de um lado depende da família para que possa se integrar socialmente e, de outro lado, pode estar restrito a relações sociais limitadas, dado que a família pode ser incapaz de prepará-lo para as adversidades dos processos de socialização secundários.

Junto à família, a inclusão por meio do espaço escolar pode ser também expressiva, locus por excelência da preparação dos sujeitos para o estabelecimento de uma vida social democrática e participativa, contando com o suporte também dos órgãos envolvidos por lei 
(instâncias colegiadas) para alcançar a essa formação social. Mas o que se percebe é que, ao longo da história, a socialização tradicional não tinha como objetivo uma reflexão crítica dos problemas sociais, apenas buscava formar indivíduos capazes de suprir as necessidades capitalistas, isto é, prepará-los para o mercado de trabalho (LIMA, 2009) e, muitas vezes, a escola acabava sendo mais um lugar onde a estigmatização e exclusão se evidenciam, quando não considerados os papeis dos diferentes agentes sociais nesse espaço de socialização. É, pois, necessário compreendermos que a educação deve ser vista como um processo amplo e abrangente, que visa transmitir conhecimentos, valores, ideias e crenças e, por isso, é fundamental na inclusão, desenvolvimento e integração de minorias sociais, uma vez que, enquanto processo, vai além das paredes das instituições de ensino e aprendizagem.

As organizações de trabalho - sistemas complexos, dinâmicos, marcados por diferentes sujeitos em interação a partir da divisão de tarefas e que desempenham funções especificas para contribuírem para a concretização de um propósito da organização constituem-se também como locus para a inclusão e integração de minorias sociais, por meio de práticas que se voltam às condições materiais concretas de existência. Entretanto, é necessário apontarmos aqui que há impasses na questão da inclusão social nesses espaços, também marcados por poderes, racionalidades, lugares e políticas, de maneira que, em muitos casos, há apenas a inserção ou introdução dos "diferentes" na estrutura organizacional, e sua permanência se dá de forma marginal, sem reais possibilidades de integração e desenvolvimento de suas capacitações. Nesse sentido, não podemos considerar inserção como sinônimo de inclusão, visto que, nesta primeira, as diferenças podem continuar evidenciadas na demarcação das possibilidades de ascensão.

Saraiva e Irigaray (2009) destacam a preocupação capitalista sobre a gestão da diversidade, mas ressaltam a inexistência de um efetivo comprometimento social, comumente apregoado em discurso. A visão da empresa, em análise pelos pesquisadores, seria aproveitar ao máximo o potencial dessas diversidades em prol do crescimento e lucratividade. A empresa busca, então, se libertar de valores sociais tradicionalmente praticados e aceitos para se modernizar, o que passa pelo caminho da inserção da diversidade social.

\footnotetext{
Abre-se, então, a contradição própria da gestão da diversidade nas empresas: se por um lado o discurso pela diversidade é aparente, falseável, pois que em essência é justificado pela obtenção de resultados positivos, por outro pode servir de eliciador ao reconhecimento das minorias sociais, reduzindo a sua invisibilidade (MAGALHÃES, 2014, p.10).
}

A inserção é, ao menos, um avanço em relação à exclusão. Assim, mesmo que hoje a sociedade se torne cada vez mais democrática, de acordo com Sandroni (1995, p. 18), o mercado de trabalho capitalista ainda "não se interessa pela pessoa do trabalhador, apenas pela capacidade de trabalho que comprou".

Um trabalhador que tenha algum tipo de limitação, como no caso da pessoa com deficiência, gera dúvidas aos empregadores sobre sua capacidade de trabalho e sobre a qualidade na realização da alguma atividade. O mesmo se refere às pessoas com baixa instrução. Os empregadores duvidam dessa capacidade por acreditarem que as instituições de educação e o investimento no desenvolvimento e na qualificação ainda são falhas (TANAKA; MANZINI, 2005), além dos preconceitos construídos nas práticas e representações sociais que dão base à própria cultura geral. Essa mesma realidade é extensiva a negros, mulheres, homossexuais e pessoas de baixa renda. Embora todos os sujeitos que são aqui tomados como minorias tenham caraterísticas distintas e, por isso, disponham de recursos diversificados para 
exercer seu poder de ação na estrutura social, a estigmatização é recorrente, tendo em vista o estabelecimento de um ideal eugenista nas organizações de trabalho.

Assim, a inclusão de minorias no mercado de trabalho requer práticas de gestão em que a pessoa é valorizada a partir de um olhar psicossocial. A diferença se torna apenas mais uma característica e que não deve ser a mais importante, já que todo sujeito social possui limites e capacitações para as mais variadas atividades. Saber identificar as competências, alocar os sujeitos em lugares adequados e proporcionar-lhes condições gerais para seu desenvolvimento e potencialização de capacidades é tarefa essencial à gestão de pessoas. Neste sentido, os desafios ainda são notáveis quanto à inclusão de sujeitos marginalizados. Ao que parece, a maior parte das organizações apenas cumpre determinações legais e utiliza-se das mesmas para o reforço da imagem social atrelada à responsabilidade - como no caso da inclusão de jovens aprendizes e de pessoas com deficiência -, criando oportunidades marginais de trabalho, sem oportunidades efetivas de crescimento pessoal e potencialização de suas capacitações.

O trabalho deve proporcionar um papel social produtivo e, ao mesmo tempo, deve ser uma forma de convívio social, uma maneira de desenvolver a capacidade e influenciar positivamente na autoestima da pessoa. Dada sua função ontológica, ou seja, considerando que, pelo trabalho, os sujeitos sociais têm a possibilidade de transformarem o contexto à sua volta e desenvolverem-se em espaços relacionais, as mudanças no ambiente de trabalho podem refletir mudanças significativas em diversas instâncias de sociedade, como um todo. Essa função essencial ganha status qualitativo se nas organizações a exclusão e o estigma possam ser amenizados com o surgimento de novos olhares, novos valores e novas atitudes, desafio constante e que se torna a problematização central neste estudo.

Importante entendermos que em meio às práticas organizacionais configuram-se ideologias que orientam as relações entre os sujeitos e que muitas vezes suas consciências de si e de mundo podem estar turvas, obnubiladas, de modo a favorecer que alguns elementos essenciais na construção da realidade escapem aos sujeitos produtores dessa mesma realidade. No que se refere à inserção e à gestão da diversidade nas organizações, poderíamos entender que a contradição essencial que marca os fenômenos está na forma como se entrelaçam a dimensão concreta (dificuldade de acessos a grupos marginalizados) e a dimensão simbólica (discursos de inclusão e de igualdade). Sem uma exata percepção da verdadeira constituição sócio-histórica das minorias, mais difíceis se tornam as possibilidades de emancipação. Seguindo a proposição de Freire (2005), numa formação sem crítica, o sonho daqueles que um dia foram oprimidos é de um dia tornarem-se os opressores.

\section{OS JOVENS EM SITUAÇÃO DE VULNERABILIDADE E O MERCADO DE TRABALHO}

Para que seja possível a segmentação de políticas e serviços públicos que atendam às especificidades de determinada faixa da sociedade, a distribuição da população por grupos etários torna-se necessária, de forma a melhor atender aos interesses de cada grupo e também incrementar o conhecimento sobre a oferta da força de trabalho. Em todas as sociedades, a idade aparece como um dos eixos ordenadores da atividade social, integrando classificações que apresentam estruturação de sentido. Todavia, os conceitos geralmente utilizados nas segmentações etárias são ambíguos e difíceis de definir, visto que as categorias criança, jovem, adulto e idoso são imprecisas e com limites difusos. Nesse sentido, as características que definem a juventude apresentam um caráter histórico-social, pois dependem da sociedade e da época em que tal estruturação é estabelecida, de forma a incorporar as responsabilidades 
e os direitos socialmente acentuados para cada grupo etário (MINAYO-GOMES; MEIRELLES, 1997; CAMARANO et al., 2003; MARGULIS; URRESTI, 2008).

A Organização das Nações Unidas (ONU), o Instituto Brasileiro de Geografia e Estatística (IBGE) e a Organização Mundial da Saúde (OMS) caracterizam a juventude como aplicável à população de 15 a 24 anos de idade. Considerando este parâmetro, a população jovem mundial possui grande expressividade, atingindo no ano de 2010 o contingente de 1,02 bilhão de pessoas (UNVPA, 2010). Conforme ressaltam Camarano et al. (2003), considerando-se as faixas etárias adolescência/juventude, adultos e idosos, um dos principais elementos sociais responsável pela transição entre um grupo e outro ocorre, primordialmente, por meio do mercado de trabalho: a inserção e o retiro.

Quanto à inserção precoce de jovens menores de idade no mercado de trabalho, de acordo com Minayo-Gomes e Meirelles (1997), seu principal elemento explicativo é a pobreza, visto que essa inserção emana de uma decisão familiar, na qual os adultos têm um peso maior. Assim, numa estratégia de sobrevivência econômica das famílias mais pobres, o trabalho precoce impõe custos sociais aos mais jovens, como a renúncia a um grau de escolarização maior (o que lhes poderia assegurar melhor colocação futura no mercado de trabalho), sobrecarga de tarefas (as quais impõem desgastes físico e mental), além da redução dos períodos de lazer. De outro lado, observamos que, no contexto da estratificação social das famílias de maior renda, a transição da infância/juventude para a vida adulta tem acontecido cada vez mais tarde, conforme se percebe na tendência do adiamento da idade em que os filhos saem da casa dos pais e constituem a própria família (CHIESI; MARTINELLI, 1997; CAMARANO et al., 2003).

Importante levarmos em conta a precariedade das condições e dos contextos laborais que usualmente estão inseridos os jovens trabalhadores, em situações marcadas pela informalidade, desemprego e ausência de condições de salubridade. Tais condições podem explicar a afirmação de Thomé, Telmo e Koller, (2010), de que o ingresso dos jovens no mercado de trabalho inicia-se geralmente com vínculos ocupacionais frágeis e vão se fortalecendo ao longo do tempo. Para as autoras, a vivência profissional ultrapassa os limites do trabalho, visto que influencia o modo de pensar e agir dos indivíduos não apenas no seu cotidiano laboral, como também em sua vida familiar e comunitária.

O modelo cultural vigente possui forte centralidade na ética do trabalho, sendo, para os jovens, a experiência ou inexperiência no mercado de trabalho um fator decisivo da sua redefinição identitária e do seu ritmo de vida, distinguindo claramente o seu tempo produtivo do tempo de lazer. Nesse sentido, o trabalho constitui um influente aspecto de normatividade e socialização, comportando, para além da dimensão instrumental (fonte de renda), uma dimensão expressiva (realização pessoal). Ao se levar em conta essas dimensões, notamos que o critério afetivo - gostar do trabalho e se sentir bem no mesmo - tem uma importância por vezes equivalente ou superior à remuneração recebida para o jovem trabalhador permanecer em seu emprego (BAJOIT; FRANSSEN, 1997).

Almeida e Silva (2004) ressaltam em sua pesquisa um ponto interessante quanto ao que representa o trabalho do jovem para parcela da sociedade, principalmente quando este jovem advém de classes menos favorecidas. É a visão do trabalho como proteção à marginalidade e à violência, uma alternativa para o jovem sustentar a si próprio e/ou à sua família e não se envolver com o crime. Os autores apontam ainda que a possibilidade de adquirir bens de consumo se mostra um imperativo para os jovens, um reflexo da lógica de consumo vigente. Nessa lógica, o desejo de aquisição de bens de consumo envolve também o desejo de se sentir incluído na cultura do consumismo, de modo que "as estratégias para alcançar tal 'direito de consumir' podem significar para esses jovens quase que um direito 
fundamental, mas também a privação do direito à liberdade quando as estratégias utilizadas os levam à prática do ato infracional” (ALMEIDA; SILVA, 2004, p. 99).

O trabalho, portanto, permite que os jovens experimentem a sua condição em dimensões relacionadas à sociabilidade, ao lazer, à cultura e ao consumo, o que acarreta numa significação comumente positiva em relação ao trabalho, por possibilitar maior independência em relação à família e proporcionar a satisfação de prazeres (SPOSITO, 2003). A partir dessas constatações, reiteramos que a valoração positiva em relação ao trabalho costuma estar mais ligada ao que ele pode proporcionar ao jovem do que ao conteúdo próprio deste trabalho, pois usualmente os jovens se inserem em ocupações que oferecem poucas condições para uma qualidade de vida laboral plena.

$\mathrm{Na}$ sociedade brasileira, a heterogeneidade e as desigualdades vigentes refletem a situação dos jovens, em especial no que tange ao acesso a direitos, bens e serviços. Considerando o contexto histórico do país, quando se verifica a situação das mulheres, dos negros de ambos os sexos, bem como os de baixa renda que vivem em periferias ou em determinadas zonas rurais, os efeitos da exclusão social são mais intensos, sendo comum o desemprego ou o subemprego de baixa qualidade (OIT, 2009). Uma das principais ações lançadas pelo Governo Federal para a ampliação do acesso ao primeiro emprego de jovens em situação socioeconômica pouco favorecida foi a consolidação da Lei de Aprendizagem. A lei de $n^{\circ} 10.097 / 2000$, ampliada pelo Decreto Federal $n^{\circ} 5.598 / 2005$, determina que todas as empresas de médio e grande porte contratem um número de aprendizes que corresponda de $5 \%$ a $15 \%$ do quadro total de empregados, em funções que demandem formação profissional. Aos aprendizes, que devem ter a idade entre 14 a 24 anos, é garantida a remuneração compatível ao salário mínimo - proporcional ao número de horas trabalhadas - e um contrato de trabalho com duração máxima de dois anos. No regime de aprendizagem, a jornada de trabalho não deve ser superior a seis horas diárias, admitindo-se oito horas para os aprendizes que já tiverem completado o Ensino Médio, se nessa jornada forem computadas as horas destinadas à aprendizagem teórica.

Nesta pesquisa, os jovens trabalhadores abordados fazem parte do público de aprendizes contemplados pela lei supracitada, como participantes de uma organização intermediadora entre jovens aprendizes e empresas que atuam na região metropolitana de Belo Horizonte. Para a triagem na seleção dos candidatos a entrarem na instituição, é feita uma análise dos jovens que estão em situação de vulnerabilidade social, tais como os de baixa renda familiar e os deficientes físicos, aos quais é assegurada prioridade.

Partimos do pressuposto que o jovem trabalhador em situação de vulnerabilidade tende a enfrentar, pelo exposto nos parágrafos anteriores, situações específicas quando de seu ingresso no mercado de trabalho. Se, por um lado, as estratégias de inserção pelo Programa Jovem Aprendiz abrem condições para a integração ao mercado de trabalho, por outro, exatamente por serem esses jovens marcados por atributos tidos como socialmente negativos (características raciais, socioeconômicas e a própria condição de jovem), a inserção pode não garantir de fato condições de integração, visibilidade e desenvolvimento pelo trabalho. Esses sujeitos, por vivenciarem o momento em que se dá a constituição de referenciais morais e subjetivos, podem estar suscetíveis à influência de estratégias de dominação que operam por meio do falseamento da realidade quando da valorização do trabalhador nos discursos organizacionais (SIQUEIRA, 2009).

Nesse sentido, a inclusão social implica democratização dos espaços sociais, a crença na diversidade como valor. Incluir não é apenas colocar junto, e, principalmente, não é negar a diferença, mas respeitá-la como constitutiva do humano. Se, em aparência, a afirmação das diferenças se apresenta de forma antiética e discriminatória, por outro lado ela pode auxiliar na sensibilização dos 
sujeitos sociais quanto à aceitação das diferenças como premissa básica na criação de vínculos e laços sociais, o que poderia amenizar a exclusão, a intolerância e a injustiça (MAGALHÃES, 2014, p.13).

Tomamos a premissa de que quanto maior a consciência do sujeito advindo de minorias sociais em relação às formas de subordinação, maiores e mais refinadas podem ser as estratégias de resistência na organização, o que pode criar situações, em meio às práticas e relações cotidianas, que façam valer de fato a diversidade e a inclusão social como forma de mudança efetiva.

\section{METODOLOGIA}

Com o propósito de alcançar o objetivo da pesquisa, realizamos uma investigação de abordagem qualitativa, a qual é caracterizada como capaz de produzir resultados não atingíveis por meio de procedimentos estatísticos ou de outras formas de quantificação. Neste sentido, a pesquisa qualitativa busca compreender os fenômenos a partir de dados descritivos sobre sujeitos, espaços e processos interativos, os quais são absorvidos a partir das análises que advêm do contato direto do pesquisador com o seu objeto de estudo (GODOY, 1995, p. $58)$.

Ademais, ressaltamos mais uma vez a perspectiva crítica quanto à natureza epistemológica deste trabalho, que busca analisar as contradições inerentes ao processo de construção da realidade social concreta, com foco na emancipação dos sujeitos sociais. Esperamos que o trabalho de pesquisa sirva de instrumento para a mudança social (PAULA, 2008). Nesse sentido, trata-se de um estudo explicativo-descritivo, já que se volta à análise dos fenômenos, identificando causalidades e contradições que lhes são próprias, através da análise proporcionada pelo tipo de abordagem escolhida, no caso deste trabalho, de natureza qualitativa (GIL, 2009).

Para a compreensão da percepção dos jovens com relação à inclusão de minorias nos ambientes de trabalho, foram conduzidas entrevistas baseadas em roteiros semiestruturados com esses sujeitos. Os jovens trabalhadores participantes da associação intermediadora de Belo Horizonte foram selecionados de acordo com sua disponibilidade em conceder a entrevista no momento da visita dos pesquisadores à associação - critério de acessibilidade e disposição voluntária daqueles que quiseram participar da pesquisa. O tempo de entrevista foi limitado em função da liberação dos jovens de suas atividades de formação ministradas na unidade de Belo Horizonte, sendo a duração média de 45 minutos cada entrevista. A quantidade de entrevistas seguiu o critério de saturação de dados (GIL, 2009), ou seja, encerrou-se o processo quando as informações se tornaram repetitivas e o material coletado já era suficiente para as análises. O Quadro 1 sintetiza a caracterização demográfica dos jovens abordados. 
Quadro 1 - Perfil dos sujeitos da pesquisa

\begin{tabular}{|l|l|l|l|l|l|l|}
\hline Sujeito & Sexo & Idade & Setor de trabalho & $\begin{array}{c}\text { Tempo de } \\
\text { trabalho }\end{array}$ & Cor de pele & \multicolumn{1}{|c|}{$\begin{array}{c}\text { Orientação } \\
\text { sexual }\end{array}$} \\
\hline E1 & Feminino & 19 & Serviços adm. em banco & 10 meses & Preta & Homossexual \\
\hline E2 & Masculino & 19 & Serviços adm. em varejo & 09 meses & Parda & Heterossexual \\
\hline E3 & Masculino & 18 & Serviços adm. em escola & 08 meses & Branca & Heterossexual \\
\hline E4 & Feminino & 19 & Serviços adm. em RH & 08 meses & Parda & Heterossexual \\
\hline E5 & Masculino & 21 & Serviços adm. em banco & 02 meses & Preta & Heterossexual \\
\hline E6 & Feminino & 20 & Serviços adm. em banco & 04 meses & Preta & Homossexual \\
\hline E7 & Masculino & 20 & Serviços adm. em aeroporto & 01 meses & Parda & Heterossexual \\
\hline E8 & Feminino & 18 & Serviços adm. em banco & 05 meses & Parda & Heterossexual \\
\hline E9 & Masculino & 21 & Serviços adm. em indústria & 08 meses & Branca & Heterossexual \\
\hline E10 & Masculino & 19 & Suporte em informática & 05 meses & Parda & Heterossexual \\
\hline E11 & Feminino & 18 & Serviços adm. em varejo & 11 meses & Parda & Heterossexual \\
\hline E12 & Feminino & 18 & Serviços adm. em aeroporto & 04 meses & Parda & Heterossexual \\
\hline E13 & Feminino & 19 & Serviços adm. em banco & 07 meses & Preta & Heterossexual \\
\hline E14 & Masculino & 18 & Serviços adm. em faculdade & 05 meses & Parda & Heterossexual \\
\hline E15 & Feminino & 22 & Serviços adm. em banco & 08 meses & Parda & Heterossexual \\
\hline E16 & Feminino & 18 & Serviços adm. em contabilidade & 06 meses & Preta & Heterossexual \\
\hline
\end{tabular}

Nota: Todas as informações foram autodeclaradas pelos sujeitos

Fonte: Dados da pesquisa

Conforme se nota, a maioria dos sujeitos se declara pardo(a), heterossexual, trabalha em organizações bancárias, com tempo médio de trabalho de seis meses, estando na faixa etária entre 18 e 22 anos. Para o tratamento e análise dos dados advindos das entrevistas com os jovens, foi utilizada a técnica da análise de conteúdo, pautada no referencial fornecido por Bardin (2004). Chizzotti (2006, p. 98) afirma que "o objetivo da análise de conteúdo é compreender criticamente o sentido das comunicações, seu conteúdo manifesto ou latente, as significações explícitas ou ocultas”. Já Colbari (2014) ressalta que, quando incorporada aos métodos qualitativos, a análise de conteúdo pressupõe e realiza os postulados presentes no paradigma interpretativo, dentre os quais podem ser ressaltados:

a resistência à "naturalização" do mundo social; a relevância do conceito de mundo da vida; a passagem da observação à compreensão; e a dupla hermenêutica, a do senso comum e a da explicação científica. Nesse empreendimento, a linguagem não é uma apenas uma forma de expressão, mas também uma forma de produção e reprodução do mundo social (COLBARI, 2014, p. 267).

Assim, como ponto de partida para a análise de conteúdo dos dados da pesquisa, temse a mensagem verbalizada pelo público a ser abordado, contudo, não será desconsiderada a relação que vincula a emissão das mensagens às condições contextuais nas quais os seus produtores se encontram (FRANCO, 2008). Assim, partimos para apresentação da análise e discussão do material coletado.

\section{ANÁLISE E DISCUSSÃO DOS RESULTADOS}

Após a escuta e a transcrição detalhada do material coletado com os jovens que entrevistamos, realizamos a análise de conteúdo a partir da identificação de categorias de análise segundo o objetivo da pesquisa e do referencial que lhe serve de base, assim como segundo a expressividade de conteúdos nas falas dos sujeitos entrevistados. O Quadro 2 sintetiza o trabalho de análise, possibilitando compreender a compilação dos dados: 
Quadro 2 - Processo de análise de conteúdo

\begin{tabular}{|c|c|c|c|}
\hline $\begin{array}{c}\text { Eixos } \\
\text { Temáticos }\end{array}$ & Categorias & Síntese do Conteúdo & $\begin{array}{l}\text { Frequência nas } \\
\text { entrevistas }\end{array}$ \\
\hline \multirow{3}{*}{$\begin{array}{l}\text { Percepção dos } \\
\text { Sentidos do } \\
\text { Trabalho }\end{array}$} & $\begin{array}{l}\text { Constituição } \\
\text { identitária }\end{array}$ & $\begin{array}{l}\text { Afirmação de aspectos de formação de } \\
\text { personalidade, como: racionalidade; } \\
\text { responsabilidade; habilidade interpessoal. }\end{array}$ & E1, E2 \\
\hline & $\begin{array}{l}\text { Remuneração e } \\
\text { demais aspectos } \\
\text { materiais }\end{array}$ & $\begin{array}{l}\text { Afirmação de aspectos instrumentais, como: } \\
\text { estabilidade financeira; aquisição de bens de } \\
\text { consumo; realização de planos pessoais. }\end{array}$ & $\begin{array}{l}\text { E4, E6, E8, E9, E12, } \\
\text { E13, E16 }\end{array}$ \\
\hline & $\begin{array}{l}\text { Aprendizagem e } \\
\text { experiência }\end{array}$ & $\begin{array}{l}\text { Afirmação de aspectos de desenvolvimento } \\
\text { profissional, como: experiência no mercado de } \\
\text { trabalho; aprendizagem profissional. }\end{array}$ & $\begin{array}{l}\text { E1, E2, E3, E5, E7, } \\
\text { E9, E10, E11, E13, } \\
\text { E14, E15 }\end{array}$ \\
\hline \multirow{11}{*}{$\begin{array}{l}\text { Percepção da } \\
\text { discriminação } \\
\text { no local de } \\
\text { trabalho }\end{array}$} & \multirow[t]{2}{*}{ Por gênero } & $\begin{array}{l}\text { Percebem que homens e mulheres são tratados } \\
\text { igualmente na organização onde trabalham. }\end{array}$ & $\begin{array}{c}\mathrm{E} 1, \mathrm{E} 2, \mathrm{E} 3, \mathrm{E} 4, \mathrm{E} 5 \\
\mathrm{E} 7, \mathrm{E} 8, \mathrm{E} 9, \mathrm{E} 10 \\
\mathrm{E} 11, \mathrm{E} 13, \mathrm{E} 15, \mathrm{E} 16\end{array}$ \\
\hline & & $\begin{array}{l}\text { Percebem aspectos discriminatórios em relação às } \\
\text { mulheres no local de trabalho. }\end{array}$ & E6, E12 \\
\hline & \multirow[t]{2}{*}{ Por cor de pele } & $\begin{array}{l}\text { Percebem não haver diferenciação no tratamento } \\
\text { dispensado aos empregados negros ou pardos. }\end{array}$ & $\begin{array}{l}\text { E1, E2, E3, E4, E6, } \\
\text { E7, E8, E9, E10, } \\
\text { E11, E13, E14, E15, } \\
\text { E16 }\end{array}$ \\
\hline & & $\begin{array}{l}\text { Percebem aspectos discriminatórios em relação aos } \\
\text { negros ou pardos no local de trabalho. }\end{array}$ & E5, E12 \\
\hline & \multirow{2}{*}{$\begin{array}{l}\text { Por condição } \\
\text { socioeconômica }\end{array}$} & $\begin{array}{l}\text { Percebem não haver discriminação em relação às } \\
\text { pessoas de classes sociais mais baixas. }\end{array}$ & $\begin{array}{c}\mathrm{E} 1, \mathrm{E} 2, \mathrm{E} 3, \mathrm{E} 4, \mathrm{E} 5, \\
\mathrm{E} 6, \mathrm{E} 7, \mathrm{E} 8, \mathrm{E} 9, \mathrm{E} 10, \\
\mathrm{E} 11, \mathrm{E} 14, \mathrm{E} 15, \mathrm{E} 16\end{array}$ \\
\hline & & $\begin{array}{l}\text { Percebem aspectos discriminatórios em relação às } \\
\text { pessoas de classes sociais mais baixas. }\end{array}$ & E12, E13 \\
\hline & \multirow{3}{*}{$\begin{array}{l}\text { Por orientação } \\
\text { sexual }\end{array}$} & $\begin{array}{c}\text { Declaram não haver homossexuais assumidos onde } \\
\text { trabalham. }\end{array}$ & $\begin{array}{l}\text { E2, E3, E8, E12, } \\
\text { E14, E15 }\end{array}$ \\
\hline & & $\begin{array}{l}\text { Percebem não haver discriminação em relação aos } \\
\text { homossexuais onde trabalham. }\end{array}$ & $\begin{array}{l}\text { E4, E5, E7, E9, E10, } \\
\text { E13, E16 }\end{array}$ \\
\hline & & $\begin{array}{l}\text { Percebem aspectos discriminatórios relativos à } \\
\text { orientação sexual no local de trabalho. }\end{array}$ & E1, E6 \\
\hline & \multirow{2}{*}{$\begin{array}{l}\text { Em relação ao } \\
\text { próprio jovem } \\
\text { no local de } \\
\text { trabalho }\end{array}$} & $\begin{array}{l}\text { Declaram nunca terem sofrido preconceito onde } \\
\text { trabalham. }\end{array}$ & $\begin{array}{l}\mathrm{E} 2, \mathrm{E} 3, \mathrm{E} 4, \mathrm{E} 5, \mathrm{E} 7 \\
\mathrm{E} 8, \mathrm{E} 9, \mathrm{E} 10, \mathrm{E} 11 \\
\mathrm{E} 13\end{array}$ \\
\hline & & $\begin{array}{l}\text { Percebem que já sofreram preconceito no local onde } \\
\text { trabalham. }\end{array}$ & $\begin{array}{l}\text { E1, E6, E12, E14, } \\
\text { E15, E16 }\end{array}$ \\
\hline \multirow{3}{*}{$\begin{array}{l}\text { Percepção das } \\
\text { possibilidades } \\
\text { de inclusão e } \\
\text { superação dos } \\
\text { preconceitos }\end{array}$} & $\begin{array}{l}\text { A partir do nível } \\
\text { individual }\end{array}$ & $\begin{array}{c}\text { Enfatizam o nível individual, como: respeitar a } \\
\text { diferença do outro; repensar estereótipos; as próprias } \\
\text { minorias demonstrarem sua competência. }\end{array}$ & $\begin{array}{l}\text { E1, E5, E6, E8, E11, } \\
\quad \text { E14, E15, E16 }\end{array}$ \\
\hline & $\begin{array}{l}\text { A partir do nível } \\
\text { coletivo }\end{array}$ & $\begin{array}{l}\text { Enfatizam o nível coletivo, como: conscientização } \\
\text { da população; formação de qualidade nas escolas; } \\
\text { convívio social equitativo. }\end{array}$ & E1, E3, E4, E7, E9 \\
\hline & $\begin{array}{l}\text { Por aparatos } \\
\text { político- } \\
\text { governamentais }\end{array}$ & $\begin{array}{l}\text { Enfatizam o nível legal, como: necessidade de } \\
\text { elaboração de leis específicas; aplicação das leis; } \\
\text { garantia constitucional de igualdade de direitos. }\end{array}$ & E7, E10, E12 \\
\hline
\end{tabular}

Fonte: Elaborado pelos autores.

Agrupamos as categorias de análise em eixos temáticos, de acordo os principais elementos-chaves abordados na problematização da pesquisa. Isso nos possibilitou a construção de inferências em relação a cada eixo para, assim, analisar a percepção dos jovens quanto à inclusão de minorias nas organizações de trabalho, segundo a perspectiva dos próprios jovens trabalhadores. 
No tocante ao primeiro eixo temático, voltado aos sentidos do trabalho, podemos inferir que o trabalho cria condições concretas de integração social, por permitir a obtenção de recursos materiais e simbólicos que possam ser utilizados pelos sujeitos sociais para a satisfação de suas necessidades e desejos e, assim, reestruturarem seus respectivos projetos de vida e transformar a realidade de vulnerabilidade social. Importante marcar aqui a função formadora do trabalho, uma vez que, em sua maioria, os jovens atribuem ao trabalho uma representação de aprendizagem e ampliação de conhecimentos, o que é de se esperar para um público de jovens aprendizes. Há também a ênfase de que a experiência de trabalho possibilita adaptar-se aos preceitos e exigências do âmbito organizacional - tais como a atitude racional, a impessoalidade nas relações e a capacitação técnica -, o que sugere que há no sujeito a interiorização de elementos ideológicos, num movimento de retificação subjetiva aos interesses normativos hegemônicos, embora tal evidência tenha se dado numa parcela pequena dos entrevistados.

Mais da metade dos entrevistados (E2, E5, E6, E7, E9, E12, E13, E15, E16) declararam que, anteriormente, possuíam um emprego regime CLT - atuando principalmente em comércio e telemarketing -, porém, optaram por aderir ao programa Jovem Aprendiz em função da possibilidade de maior tempo aos estudos (a carga horária é menor do que um emprego integral) e também por ser uma das poucas oportunidades de ingresso numa empresa de grande porte. Assim, acreditam que mesmo com o custo de oportunidade de um salário maior, a opção é compensadora quando considerada as possibilidades futuras de ascensão profissional.

Eu entrei no programa jovem aprendiz porque eu não conseguia entrar numa empresa boa. Meus empregos sempre foram... Não empregos bons. Era supermercado, padaria... Eu não tinha tempo pra mim, nem para minha família e vi então que aquilo não tinha futuro nenhum. Se eu vivesse em prol daquilo e tivesse um crescimento, aí com certeza eu ficaria. Mas, com isso, eu fui sujando minha carteira. Aí a solução que eu me vi, foi entrar no programa Jovem Aprendiz, porque aí eu vou ter quinze meses numa empresa boa e por mais que eu não seja efetivado (...), eu vou ter já uma experiência naquilo. E isso ajuda a limpar minha carteira, né? (E9)

Quinze dos dezesseis entrevistados atuam em áreas administrativas. Porém, muitos deles tinham outros interesses profissionais, como se formarem para atuar como médico (E3, E12), psicólogo (E4), técnico em mineração (E5), nutricionista (E8, E11) e publicitário (E9). Diante da realidade permeada por limitações, estes passam a considerar o investimento em um curso superior de Administração, dada a experiência profissional que eles estão tendo, compreendendo que as suas condições socioeconômicas não possibilitam determinados tipos de planos ou sonhos.

Eu tinha vontade de fazer uma medicina, sabe? Só que com o salário que eu vou ganhar eu não vou ter condição, né? (...) Então eu escolhi mais uma coisa mais simples, entendeu? Então tá aí a dificuldade, porque nem tudo que você quer, você vai ser. (E3)

A compreensão desse cenário ajuda a entender alguns dos motivos que fazem do curso de Administração possuir o maior número de graduandos no Brasil (segundo dados do Censo da Educação Superior em 2013), pois além de representar para vários jovens a segunda opção (e única possível) e estar atrelado à sua vivência profissional, quando consideradas as instituições de ensino privadas, seu custo tende a ser menor do que os cursos que exigem sofisticadas estruturas didáticas, como é o caso dos cursos nas áreas de saúde e engenharias. 
Em função do capital cultural desses sujeitos (BOURDIEU, 2007), os jovens aprendizes tomam consciência das reais possibilidades que possuem para o alcance da própria ascensão social.

No segundo eixo temático, voltado à maneira como percebem as práticas de discriminação social, na categoria em relação à questão do gênero, notamos pelos relatos que há uma ideia geral de que homens e mulheres são iguais em termos de possibilidades gerais. Assim, sugerem a universalização como mecanismo de operação ideológica (GUARESCHI, 2002), à medida que se tomam por iguais sujeitos que nas práticas sociais concretas se hierarquizam e se diferenciam em relações de dominação e submissão. Foi frequente no relato dos entrevistados a situação de terem sido educados apenas pela mãe, o que também parece reforçar a não concordância com os estereótipos atribuídos à fragilidade e dependência da figura feminina. No âmbito do trabalho atual, apenas dois sujeitos - ambos do sexo feminino - enfatizam a percepção da discriminação por gênero, apontando para a pouca presença de mulheres no local de trabalho (E12) e ao tratamento ríspido que algumas desproporcionalmente recebem (E6).

Ainda no mesmo eixo temático, em relação à discriminação por cor de pele, quase todos os sujeitos afirmam a existência de práticas de exclusão e discriminação racial na sociedade, embora não saibam evidenciar de forma aprofundada como essas práticas se concretizam na estrutura social. Se na visão deles o preconceito racial é notado no contexto social amplo, o mesmo não ocorre em relação ao atual espaço laboral. Este panorama nos sugere que em meios sociais marcados por maior racionalidade das práticas, como nas organizações de trabalho, o estabelecimento de leis e demais medidas protetivas garantem algum amparo aos sujeitos que se constituem como minorias sociais, haja vista o fato de a discriminação racial poder trazer danos significativos - tanto materiais quanto simbólicos - às organizações e à sua imagem corporativa externa. Foi possível notar ainda alguns discursos (E3, E4, E5, E10, E11, E15) de incorporação ideológica que banaliza as práticas sociais opressivas, culpabilizando as próprias minorias quanto à sua exclusão.

Lá não tem negros... Mas eu acho que, assim... Uma vez uma cliente falou comigo assim: 'Como você fez para entrar aqui?' . Aí eu falei que eu conheci uma gerente e que depois conheci a (associação intermediadora)... E ela falou assim: 'Porque minha filha quer muito trabalhar em banco, só que eu já falei com ela pra parar de sonhar com isso, porque negros não trabalham em banco'. Isso pra mim tá totalmente errado, porque eu já vi chefes negros, então, assim, até as próprias pessoas têm esse preconceito. (E15)

Notamos nesse depoimento que a jovem, que se autodeclarou como parda, ignora o fator da exclusão ao relatar que não há negros onde trabalha, não aprofundando nos motivos envoltos a essa ausência. Posteriormente, ela toma as exceções - existir chefes negros - como regra, incorporando uma justificativa ideológica que nega a discriminação e reforça o conceito de democracia racial (BERNARDINO, 2002), generalizando sujeitos que apresentam diferenças históricas nas possibilidades de acessos e ascensão social. Dentre os que percebem o preconceito em função da cor de pele, um sujeito (E5) apontou que houve casos de clientes que não quiseram ser atendidos por negros e outro sujeito (E12) destacou a ausência de líderes negros na organização de trabalho.

Em relação à categoria condição socioeconômica, ainda no mesmo eixo temático, boa parte dos entrevistados enfatiza a existência de diferenciações no tratamento em relação às pessoas de classes sociais menos favorecidas, muito embora haja a percepção de tais ações discriminatórias em outros espaços de socialização, mas não na organização em que trabalham. Expressam ainda que as possibilidades de mudança dependem de como tais 
sujeitos - no caso, os de classes menos favorecidas - conseguem, por mérito, vencer frente às adversidades sociais, numa espécie de mitificação heroica da ascensão e da mobilidade social. Congregando tanto a questão racial quando socioeconômica, há um depoimento que é emblemático para discutir tal questão:

Lá não (há preconceito). O problema das pessoas é que elas se autodepreciam. Não só os negros. Eu tenho funcionário lá que ele próprio se chama de macaco, porque ele é negro. (...) Elas se autodepreciam: “ah, é porque eu sou pobre, nada acontece na minha vida..." A gente tem que fazer a diferença. (E4)

Percebemos que o sujeito E4 já assume em sua fala a posição da própria empresa, se utilizando da expressão "eu tenho funcionário", o que indica grande identificação e personificação da ideologia organizacional. Poderíamos inferir ainda que a mitificação da possibilidade de ascensão social está também atrelada ao desejo de corresponder socialmente às prescrições de algumas instituições sociais, para além do ideário das organizações de trabalho. Ao enfatizar a questão da autodepreciação como suficiente, a entrevistada desconsidera todo o contexto macrossocial de opressão aos negros e aos pobres. É preciso marcar que as estratégias ideológicas operam pelo forçoso consentimento do sujeito - mesmo que inconscientemente - em corresponder com os interesses organizacionais, na tentativa de se garantir algum gozo e realização nas práticas em que se inserem (PAGÈS et al., 1987).

Quanto à categoria que se volta à percepção da discriminação por orientação sexual, é nítida a noção de que os sujeitos sociais heterossexuais têm menor ciência de práticas de exclusão nas organizações em que se inserem. Nesse sentido, a percepção da discriminação é mais expressiva para os sujeitos que sofrem as ações de opressão, dada a possível banalização e naturalização da prática por parte de quem as efetiva. No grupo de entrevistados, apenas dois sujeitos se declaram homossexuais - e tal feito não se fez livre de desconforto ao entrevistado, o que nos sugere que o coming out (do inglês, sair do armário, termo que marca politicamente a postura dos homossexuais como prática afirmativa nos espaços sociais) não tenha se evidenciado. São eles que também registram práticas de discriminação nas empresas, com exemplificações voltadas a não-aceitação, especialmente por parte de trabalhadores de gerações anteriores e mais velhos, cuja postura conservadora tende a ser mais nítida. O exemplo da entrevistada E1, que trabalha na região metropolitana de Belo Horizonte, é profundo.

\footnotetext{
Eu, por ser (homossexual), cidade pequena também, né? Aí já me viram na rua com minha namorada e foram questionar a gerente, por conta disso. Aí ela veio conversar comigo e falou que sabe como que eu trabalho e que isso não interfere em nada. $\mathrm{E}$ independente disso... era só para evitar mesmo, porque pessoas mais antigas não entendem. Até então, não vou questionar, mas (...) procuro evitar para eu poder ser contratada, que é uma coisa que eu quero. É igual eu te falei, pra eu ter estabilidade, a gente tem que aceitar muita coisa, aí eu tive que aceitar por conta disso. (E1)
}

A intensidade da violência vivida é evidenciada pelas lágrimas da entrevistada ao relatar esta situação. A aceitação no trabalho depende, então, da adequação das características desses sujeitos aos padrões hegemônicos de perfis profissionais, normalmente associados a pessoas que sejam homens (já que a mulher seria estereotipada à dimensão do afeto, da subjetividade e da ausência de atuação competitiva), heterossexuais (visto que ao homossexual se associa a imagem de depravação, anomalia e promiscuidade), experientes (pois os jovens investem em outras áreas que podem colocar a moralidade em xeque, tais como as vivências da sexualidade), e com imagens pessoais coerentes com o que se preconiza 
institucionalmente (por uma questão de idealização e objetificação do desejo de reconhecimento). Como não podem atender totalmente a este perfil, os jovens aprendizes são impelidos a buscar, ao máximo, se aproximar do padrão estabelecido.

Em relação à vivência do preconceito pelo próprio jovem, a maioria declara nunca ter sido discriminada no ambiente de trabalho - contudo, não houve relatos que apontassem para práticas de sensibilização dos demais funcionários da empresa para a sua real inclusão. Dentre os seis que declaram já terem sofrido preconceito, para além do relato da discriminação quanto à orientação sexual, eles destacam que o fato de serem jovens aprendizes implica em ações dos colegas de trabalho que os fazem se sentir desvalorizados e a ter que fazer funções que exigem pouco do seu potencial cognitivo. A análise do quadro captado nos permite inferir que a violência simbólica não se apresenta com grande frequência aos jovens aprendizes, todavia, possibilita também a constatação de que a percepção do preconceito se limita àquelas ações diretamente direcionadas aos jovens, os quais não demonstram consciência da conjuntura estrutural simbólica da discriminação e estigma das minorias.

No que se refere, por fim, ao eixo temático que se volta à percepção da inclusão de minorias pelo trabalho e superação dos preconceitos, nota-se que há uma maior evidenciação de discursos que marcam o nível individual de práticas para a transformação social concreta, não obstante essa pontuação seja dada de maneira vaga, sem exemplificações sobre como se articulariam os sujeitos para fazer valer seus interesses. Discursos que marcam o nível coletivo são ainda universalizantes e generalistas - no sentido de que é necessário que as pessoas, em geral, respeitem as diferenças e criem práticas de convívio social equitativas sem que se esclareçam ações concretas para o estabelecimento da mudança. Parte dos entrevistados volta a marcar os feitos e as capacitações dos sujeitos em nível individual de ação para a transformação social, sugerindo que é devido ao mérito que as reais possibilidades emergem, posto que o contexto histórico-social se apresentaria sem distinções aos diversos sujeitos que nele se inserem. Ao ser questionado sobre como superar o preconceito nas organizações, um dos entrevistados responde:

As pessoas demonstrarem, né, pelo trabalho. Você demonstrando que você é capaz, a pessoa não vai ter o que te julgar. Pra mim, eu sempre busco isso. O seu trabalho, o seu esforço... E não se preocupar com a mente limitada de ninguém que vê preconceito de incapacidade em quem não tem, quem é capaz de produzir, capaz de crescer e de ser um bom profissional. (E5)

Mais uma vez, evidenciamos a naturalização e a universalização como mecanismos de falseamento da realidade, promovendo alienação junto aos sujeitos em vulnerabilidade social. Dentre os abordados, apenas três sugerem que práticas de transformação social devam também se inscrever em contexto institucional, a partir da elaboração de políticas públicas e legislação que viabilizem de fato a transformação da estrutura social hierarquizada e desigual. Convém destacarmos que dois entrevistados (E2, E11) não souberam apontar possibilidades de inclusão social e redução dos preconceitos, o que nos sugere que a reflexão crítica pela autoanálise e pelo olhar para si não estão presentes, de fato, no cotidiano de muitos jovens trabalhadores advindos de contexto de vulnerabilidade social.

Ainda em relação às possibilidades de ascensão econômica e social dos próprios jovens abordados, importante mencionarmos um ponto revelado nas entrevistas. Quando questionados sobre a concordância com as cotas que separam vagas para pessoas negras e pessoas de baixa renda ingressarem nas universidades federais, dos 16 entrevistados, 6 jovens (E2, E3, E4, E10, E11, E15) discordam de qualquer tipo de cota, 6 jovens (E1, E5, E6, E8, E9, E12) discordam das cotas para negros e concordam com as cotas para pobres, e apenas 3 
entrevistados (E7, E13, E16) concordam com ambas as cotas - um não soube opinar. Os discursos se pautam novamente no ideal da meritocracia, com argumentos de que essas pessoas não seriam menos capazes que as outras, que as cotas poderiam ser vistas como uma forma de preconceito, além de não se haver critérios objetivos para a definição daquelas pessoas que são negras ou não.

Complementando a constatação, ressaltamos que no início das entrevistas foi perguntado aos jovens quais seriam os seus planos para a carreira profissional e todos destacaram a questão do estudo, do imperativo de se formarem em um curso de graduação superior e exercerem uma profissão. No entanto, quando interrogados sobre quais seriam os obstáculos que eles provavelmente enfrentariam para o alcance de seus objetivos profissionais, 7 jovens (E3, E7, E8, E9, E11, E12, E14) relataram a dificuldade financeira que teriam em pagar uma faculdade e, curiosamente, apenas um (E4) citou a dificuldade que teria em passar no vestibular da universidade federal. É interessante perceber então que embora haja jovens que se mostrem contrários a algumas ações afirmativas para o ingresso nas universidades públicas, a entrada deles mesmos nestes espaços se mostra tão inacessível, que sequer cogitam como dificuldade a sua entrada em tal lugar, pois sendo algo fora da sua realidade tangível, o que lhes parece mais palpável é a dificuldade que enfrentarão para pagar uma graduação em instituição privada de ensino. Nesse sentido, a universidade pública não seria uma dificuldade, mas, de fato, uma impossibilidade para os jovens em situação de vulnerabilidade social, o que nos permite refletir sobre a afirmação do sujeito E9: "A UFMG, por exemplo, não é pública de verdade".

O discurso do mérito já influencia a percepção dos jovens trabalhadores quanto à maneira como devem se ajustar às práticas organizacionais, ao mesmo tempo em que, mesmo que de forma inconsciente, já consigam compreender quais são os espaços que lhes são acessíveis ou não. Neste cenário, em que as suas atitudes se apresentam como contrárias às formas de sua própria inclusão, a alienação pode lhes custar a desconsideração de elementos políticos expressivos nas trocas sociais, especialmente em se tratando de sujeitos advindos de realidades marcadas pela vulnerabilidade e por atributos socialmente negativados. Tem-se já nesse ínterim o estabelecimento da ideologia hegemônica da inclusão e do mérito, tal como se defendeu na exposição teórica deste artigo, uma ideologia que não se mostra favorável à emancipação política, social e econômica desses sujeitos em seus contextos sociais.

\section{CONSIDERAÇÕES FINAIS}

Neste trabalho, objetivamos analisar a percepção de jovens aprendizes quanto à inclusão de minorias sociais nas organizações de trabalho. A pesquisa realizada revelou dados de certa forma esperados, mas nem por isso menos desconcertantes, sobre os quais gostaríamos de nos debruçar neste momento final do texto. Nossos achados ratificam que a inserção dos jovens em situação de vulnerabilidade social nas empresas não implica em sua formação de um pensamento crítico em relação às minorias, sendo a inserção do jovem aprendiz majoritariamente voltada ao cumprimento da legislação trabalhista.

No caso dos jovens aprendizes, sinalizamos que, embora o processo de inserção vigente não seja considerado emancipatório nem garanta ascensão social, ele promove ao menos uma atividade laboral com menor precarização em relação aos demais tipos de trabalho que essa parcela da população geralmente ocupa, possibilitando a eles uma experiência de trabalho em empresas que normalmente não estariam predispostas a recebê-los. Tal experiência poderá ser valorizada futuramente no mercado de trabalho. Num segundo momento, temos a operação ideológica na constituição subjetiva, inculcando nos sujeitos a 
interiorização de padrões hegemônicos de tipologias sociais, o que pode custar ao trabalhador submissão às avessas, no intuito de se responder às prescrições que promoveriam a valorização social e a negação identitária. Sobre isso, gostaríamos de ressaltar três aspectos.

Em primeiro lugar, gostaríamos de registrar um jogo perverso em curso na maior parte das organizações que converte discursivamente as obrigatoriedades legais em ações de responsabilidade perante a sociedade, reforçando o imaginário de positividade organizacional e de respeito ao social, quando nada mais fazem do que cumprir estritamente os termos da lei. Isso leva a que se fabrique simbolicamente organizações que se mostram abertas à inserção de jovens trabalhadores, mas que a eles negam qualquer possibilidade efetiva de ascensão e de desenvolvimento profissional. As atividades secundárias que ocupam evidenciam seu lugar de fato no contexto organizacional, embora eles sejam continuamente mobilizados para aderir ao projeto de organização que lhes promete dias melhores em um futuro impreciso. $\mathrm{O}$ desdobramento desse jogo é a conformação subjetiva de sujeitos que, mesmo distantes dos padrões hegemônicos necessários para a valorização na organização, silenciam sobre quem são como sujeitos, submetendo-se docilmente frente às promessas de realização futura.

Em segundo lugar, chama a atenção o nível de resignação dos jovens trabalhadores entrevistados. Do ajustamento inicial e concreto aos preceitos da organização, os próprios sonhos terminam sendo ajustados ao que é possível, o que fica evidenciado pelo baixo potencial de abstração na seleção mais ou menos óbvia de alternativas profissionais, como a formação superior na área de Administração. Por ser a área em que a maioria trabalha e, simultaneamente, ser um curso mais barato, ela se converte em alternativa prioritária, quando não inexorável mesmo, em um quadro de franco utilitarismo que só traduz o empobrecimento generalizado dos ingressantes. O que esperar de jovens que não sonham com o que lhes é efetivamente caro, mas apenas com o que lhes parece materialmente possível?

Isso nos leva ao terceiro e último achado que nos parece primordial. Até que ponto o mero cumprimento da legislação não deixou de fazer com que as organizações problematizassem justamente o que importa, que inclusão social não é apenas conceder um espaço profissional para jovens trabalhadores? Isso nos parece central porque como o atendimento à legislação apenas põe a questão da inserção econômica em pauta, todos os demais aspectos propriamente humanos são deixados de lado. A oportunidade deve ser abraçada sem questionamentos, porque pode qualificar os que se esforçarem o suficiente. Há um silêncio para não evidenciar que o mérito subjacente a esta dedicação esconde as condições sociais de violenta segregação com as quais esses jovens precisam lidar cotidianamente. $\mathrm{O}$ fato de serem jovens, pobres, negros e pardos, sem experiência profissional e com problemas estruturais de escolaridade se apresenta como algo indesculpável se não alcançarem o desempenho desejado, porque tudo se converte em uma questão desproblematizada de esforço e de mérito: se não alcançarem o que foi definido, se não se tornarem o que deles se espera, será pura e exclusivamente por questões individuais, jamais estruturais. Em outras palavras, brinca-se com os sonhos de inclusão, mas não se procura minimamente solucionar aspectos que objetivamente afastam tais jovens de serem efetivamente incluídos nas organizações e, também, na sociedade.

Espera-se, ao final deste trabalho, que as problematizações aqui levantadas sirvam de parâmetro para profissionais inseridos no contexto sócio-organizacional no tocante ao seu comprometimento ético e político em meio à dinâmica coletiva, de modo a atuarem especialmente quanto à gestão de pessoas e da diversidade - na promoção de um cenário mais equitativo e justo nas relações de trabalho, efetivando, de fato, a ideia de qualidade de vida no trabalho e de responsabilidade empresarial. 


\section{REFERÊNCIAS}

ALMEIDA, M. M.; SILVA, R. C. Compreendendo as estratégias de sobrevivência de jovens antes e depois da internação na FEBEM. Revista Brasileira de Orientação Profissional, Ribeirão Preto, v. 5, n. 1, p. 87-102, 2004.

BAJOIT, G.; FRANSSEN, A. O Trabalho, Busca de Sentido. Revista Brasileira de Educação, São Paulo, n. 5-6, p. 76-95, maio/dez. 1997.

BARBOSA, C. S. Habilidades excepcionais: uma avaliação das capacidades produtivas de pessoas portadoras de deficiência mental. 2007. 111 f. Dissertação (Mestrado Profissionalizante em Engenharia) - Escola de Engenharia, Universidade Federal do Rio Grande do Sul, Porto Alegre.

BARDIN, L. Análise de conteúdo. 3. ed. Lisboa: Edições 70, 2004.

BERNARDINO, J. Ação afirmativa e a rediscussão do mito da democracia racial no Brasil. Estud. afro-asiát., Rio de Janeiro, v. 24, n. 2, p. 247-273, 2002.

BOURDIEU, P. O poder simbólico. 10. ed. Rio de Janeiro: Bertrand Brasil, 2007.

CAMARANO, A. A. et al. A transição para a vida adulta: novos ou velhos desafios? Mercado de Trabalho: Conjuntura e Análise. Rio de Janeiro, n. 21, p. 53-66, fev. 2003.

CHIESI, A; MARTINELLI, A. O trabalho como escolha e oportunidade. Revista Brasileira de Educação, São Paulo, n. 5-6, p. 110-125, maio/dez. 1997.

CHIZZOTTI, A. Pesquisa em ciências humanas e sociais. 8. ed. São Paulo: Cortez, 2006.

COLBARI, A. A análise de conteúdo e a pesquisa empírica qualitativa. In: SOUZA, E. M. (Org.) Metodologia e analíticas qualitativas em pesquisa organizacional: uma abordagem teórico-conceitual. Vitória: UFES, 2014.

FREIRE, P. Pedagogia do oprimido. Rio de Janeiro: Paz e Terra, 2005.

FRANCO, M. L. P. B. Análise de conteúdo. 3. ed. Brasília: Liber Livro, 2008.

GIL, A. C. Como elaborar projetos de pesquisa. São Paulo: Atlas, 2009.

GODOY, A. S. Introdução à pesquisa qualitativa e suas possibilidades. Revista de Administração de Empresas, São Paulo, v. 35, n. 2, p. 57-63, mar./abr. 1995.

GOFFMAN, E. Estigma - notas sobre a manipulação da identidade deteriorada. 4. ed. Rio de Janeiro: Guanabara, 1988.

GUARESCHI, P. A. Ideologia. In: JACQUES, M. G. et al. Psicologia social contemporânea. 7. ed. Petrópolis: Vozes, 2002. p. 89-103.

LIMA, L. C. Interação família-escola: papel da família no processo ensino-aprendizagem. Londrina: Secretaria da Educação, 2009. 
MAGALHÃES, A. F. Contradições entre essência e aparência nos processos de empoderamento de gays em organizações de trabalho. In: ENCONTRO DA ASSOCIAÇÃO NACIONAL DE PÓS-GRADUAÇÃO E PESQUISA EM ADMINISTRAÇÃO, 38, Rio de Janeiro. Anais... Rio de Janeiro: ANPAD, 2014.

MARGULIS, M.; URRESTI, M. La juventud es más que una palabra. In: MARGULLIS, M. (Ed.). La juventud es más que una palabra: ensaios sobre cultura y juventude. Buenos Aires: Biblos, 2008. p. 13-30.

MARX, K.; ENGELS, F. A ideologia alemã. São Paulo: Martins Fontes, 2007.

MINAYO-GOMEZ, C.; MEIRELLES, Z. V. Crianças e adolescentes trabalhadores: um compromisso para a saúde coletiva. Cadernos de Saúde Pública, Rio de Janeiro, v. 13, suppl. 2, p. 135-140, jan. 1997.

OIT. ORGANIZAÇÃO INTERNACIONAL DO TRABALHO. Trabalho decente e juventude no Brasil. Brasília: OIT, 2009.

PAGÈS, M. et al. O poder das organizações. São Paulo: Atlas, 1987.

PAULA, A. P. P. Teoria crítica nas organizações. São Paulo: Thomson Learning, 2008.

SANDRONI, P. O que é mais-valia? 13. ed. São Paulo: Brasiliense, 1995.

SARAIVA, L. A. S.; IRIGARAY, H. A. R. Políticas de diversidade nas organizações: uma questão de discurso? Revista de Administração de Empresas, São Paulo, v.49, n.3, set./dez. 2009.

SIQUEIRA, M. V. S. Gestão de pessoas e discurso organizacional. 2. ed. Curitiba: Juruá, 2009.

SPOSITO, M. P. Os jovens no Brasil: desigualdades multiplicadas e novas demandas políticas. São Paulo: Ação Educativa, 2003.

TANAKA, E. D. O.; MANZINI, E. J. O que os empregadores pensam sobre o trabalho da pessoa com deficiência?. Revista Brasileira de Educação Especial, São Paulo, v. 11, n. 2, p. 273-294, maio/ago. 2005.

THOMÉ, L. D.; TELMO, A. Q.; KOLLER, S. H. Inserção laboral juvenil: contexto e opinião sobre definições de trabalho. Paidéia, Ribeirão Preto, v. 20, n. 46, p. 175-185, maio/ago. 2010.

UNVPA. Direitos da população jovem: um marco para o desenvolvimento. 2. ed. Brasília: UNVPA, 2010. 